\title{
Needs Analysis Development of Android-Based Physical Fitness Guide
}

\author{
Indah Prasetyawati Tri Purnama Sari ${ }^{1, *}$ Erwin Setyo Kriswanto ${ }^{1,}$ Jaka Sunardi ${ }^{1,}$ \\ Sigit Dwi Andrianto ${ }^{1}$
}

${ }^{1}$ Faculty of Sport Sciences, Universitas Negeri Yogyakarta, Yogyakarta, Indonesia

*Corresponding author. Email: indah_prasty@uny.ac.id

\begin{abstract}
The purpose of this study was to analyze the needs of android-based physical fitness activity guides. This study is an exploratory, descriptive study. The subjects in the study were 80 students. The study used observation sheet intrusion and questionnaires, with data retrieval techniques through surveys. Analysis of research data uses quantitative and qualitative descriptive. The results showed a decrease in people's habits during the pandemic to move actively towards sedentary lifestyle behavior. Based on the study results, it can be concluded that the development of android-based physical fitness guidelines is needed to increase the desire to move actively to support fitness. Physical fitness guides developed can guide users to perform physical fitness activities independently very quickly.
\end{abstract}

Keywords: physical fitness, android

\section{INTRODUCTION}

The purpose of this study was to analyze the need for an android-based physical fitness activity guide. This research is exploratory, descriptive analysis. The subjects in this study were 80 students. This study uses smartphones to significantly impact people's lifestyles, as many applications and services are developed and provided. The number of mobile applications that can replace or supplement exercise independently is increasing [1], [2]. One such application is an application related to physical fitness.

Physical fitness in children and adolescents (especially cardiorespiratory endurance) has declined globally over the past few decades [3]. Children and adolescents who are active in physical activity provide health benefits. These benefits include; improvement of physical fitness (cardiorespiratory and muscular fitness), cardiometabolic, health (blood pressure, dyslipidemia, glucose, and insulin resistance), bone health, cognitive outcomes (academic performance, executive function), mental health (reducing symptoms of depression); and reduce adiposity. In adults, higher amounts of sedentary behavior are associated with reduced health outcomes and all-cause mortality, cardiovascular disease and cancer mortality, and incidence of cardiovascular disease, cancer, and type 2 diabetes [4].

Physical fitness is a general fitness that describes a person's ability to live most effectively with his potential, which depends on physical, mental, emotional, social, and spiritual fitness, which are very interrelated [5]. Physical fitness is divided into two, namely Health-related components and performance or skill-related fitness. Health-related components consist of cardiorespiratory fitness, body composition, flexibility, muscle strength, muscle endurance). Meanwhile, performance or skills related to fitness include balance, reaction time, coordination, agility, speed, and strength [6], [7],[8].

The World Health Organization (WHO) has proposed some general recommendations for physical activity to combat the situation at home. These physical activity recommendations are intended for available adults with a duration of 150 minutes or 75 minutes per week. Physical activity is carried out with moderate or vigorous intensity [4]. Physical activity is also recommended to combine activities at different intensities [9].

With the current trend of increasing physical inactivity and high sitting time in society, more substantial and more concerted efforts are needed to promote physical activity and reduce sitting time. [10]. Lack of physical activity is one of the main risk 
factors for death. What's more, people who are not physically active. Today, the phenomenon of low physical activity also occurs in Indonesia[11]. Physical activity that is carried out activities to achieve fitness is essential during the current pandemic. This is because active physical activity can help to overcome this pandemic, especially in increasing body immunity and maintaining human health and quality of life [12].

The increasing number of android-based physical fitness applications related to the concept of physical exercise, especially physical fitness, is expected to help users to be able to practice independently and be able to change towards an active lifestyle. However, many questions regarding reliability, information integrity, ease of access are raised by the application. On the other hand, physical fitness applications are expected to promote healthy and active living in the community. This research aims to find out the guidelines for fitness activities that need to be developed. The results of this study are expected to provide information on physical fitness guidelines that need to be developed so that they can guide users to carry out physical fitness activities independently very easily.

\section{METHODS}

The subjects in this study were students from the health and recreation physical education study program. The number of students who participated in this study was 80 students (61 males and 19 females). Specifically, the characteristics include ages 18-23 years (mean 19.9, SD 1.07). Weight $45-83 \mathrm{~kg}$ (mean 62.7, SD 10.4), height $155-185 \mathrm{~cm}$ (mean 165.7, SD 6.9).

This research is exploratory, descriptive research. Data collection procedures involving students of the Faculty of Sports Science, Yogyakarta State University. Samples were randomly selected to participate in taking part in the research study. Data was collected through an online questionnaire sheet. The needs analysis questionnaire contains the following questions: 1) What do you know about physical fitness and physical fitness measurement guides?, 2) Have you ever read physical fitness books and physical fitness measurement guides? Have you ever taken a physical fitness test?, 3) In your opinion, has the use of conventional books (printed books, textbooks, and pocketbooks) been influential in physical fitness and physical fitness measurement? Why?, 4) How well do you understand the theory and practice of measuring physical fitness? What sources did you use to learn this?, 5) Do you have a cell phone? What type and brand of cell phone do you use?6) In a day, how often do you use your cellphone instead of using a book? Why?, 7) In your opinion, is there a need for a mobile application containing guidelines and measurements of physical fitness?, 8) During outdoor conditions, especially in physical fitness activities. In your opinion, which one is more suitable and more practical between using conventional books or using applications on mobile phones?, 9) Which do you prefer, a physical fitness measurement guide book or an application? Why?, 10) What are your suggestions for developing an androidbased physical fitness activity guide?

Data analysis in this study used quantitative and qualitative descriptive.

\section{RESULTS}

In this study, researchers developed problems related to physical fitness. This was based on the background of the considered complex problems and the issues that needed to be solved. The initial analysis was conducted through an online questionnaire to 80 adults still actively doing fitness sports in Yogyakarta.

In this study, researchers developed problems related to physical fitness. This was based on the background of the considered complex problems and the issues that needed to be solved. This requires analysis stage is carried out using a literature study and collecting information from physical fitness activists. The initial analysis was conducted through an online questionnaire to 80 adults still actively doing fitness sports in Yogyakarta.

Based on the research needs analysis results, as many as $93 \%$ stated they had heard of the actual physical fitness test. Based on questions number one and two, respondents noted that most knew several physical fitness measurement tests, including the Indonesian Physical Fitness Test (TKJI), Balke Test, Beep Test, etc. Subjects with a percentage of $96 \%$ stated that their knowledge of fitness measurement tests based on items with an index was only limited to knowing, the majority of respondents admitted that in their experience they had done it but were never given a more specific understanding of the test which caused respondents not to understand correctly.

In the general conclusion of the answer to question item number three, $64 \%$ of respondents stated the ineffectiveness of conventional/printed books in supporting the implementation of physical fitness measurement tests. Assuming that books are not practical to carry anywhere, many respondents want practicality in recording and processing results. This cannot be obtained using conventional books because they have to calculate based on formulas. However, if you use an application, you can easily input data and know the results. 
Respondents based on item number four argue that if they do not know the exact source of the book or journal, what questions can be used as a reference to obtain information about physical fitness measurements. As many as $24 \%$ of respondents answered question number two by never answering a fitness test directly. In contrast, most other respondents stated that they had taken a fitness test during the selection to become an athlete or in college. Further data based on point number five as many as $100 \%$ of respondents stated that they had used an Android-based cellphone or similar questions (ios). Based on the survey on question number six to respondents, as many as $94 \%$ of respondents admitted they interact more often using cellphones than using books every day to obtain information. This is because they think that cellphones are considered more flexible to carry and access anytime.

In addition, based on the survey answering question number seven, $92 \%$ of respondents admitted that they needed a software-based application guide that could be easily accessed on their cellphones to support fitness exercises independently. A total of $96 \%$ of respondents stated in their answer to question number eight that the guide in the form of android software is more suitable if taken when doing fitness exercises than conventional books.

In question number nine, $93 \%$ of respondents stated that they would prefer a fitness guide to a conventional book to do physical fitness exercises independently; this is also based on the fact that conventional books are vulnerable if taken to outdoor activities. The research subjects suggested making a simple physical fitness guide, the proper steps, easy to reach, enjoyable, and added visualization aids using pictures.

\section{CONCLUSION}

Result data Based on the research, it is necessary to develop an android-based physical fitness activity guide. The Android-based fitness activity guide was chosen because currently, people use Android more than conventional people. It is easier for people now to access information in it. It can facilitate people to be able to improve their fitness independently.

Smartphones have powerful computing and communication capabilities that allow machines and other data-driven analytical algorithms to personalize physical activity programs for each individual. In addition, the last few generations of smartphones have integrated powerful activity features and allowed the collection of actual physical activity data from each individual [13], [14].

Android-based physical fitness activities were chosen because Android-based applications are easily accessible to the public and are designed to record, report, report, and analyze the implementation of physical fitness measurements [11]. In addition, the Android operating system is open-source, which is very open for developers to create applications according to their individual needs so that mobile applications can be developed using free software, which Windows, Linux, and macOS support. Another reason is that more people choose to use an Androidbased smartphone than iOS because it is more affordable [15],[17]. Android-based applications also occupy more than $70 \%$ of the smartphone market in the world (Anbalahan [2]).

The research results entitled Mobile Applications for Training Plans Using Android Devices: A Systematic Review and a Taxonomy Proposal, states that mobile applications can improve the health, wellbeing of users and can be used in any scientific study [1]. Android-based physical fitness guidelines currently need to be developed, this is supported by the fact that physical fitness that is developed at the same time can have an impact on increasing aspects of literacy, motivation, and integration education to help people have better physical fitness, so they don't get tired easily when doing activities. To realize an increase in knowledge of physical fitness, which is marked by the shift of the system in an all-digital era, it is necessary to apply an Android-based physical fitness guide model that aims to increase knowledge of physical fitness in the community [17].

Smartphone applications can be a good tool in promoting physical activity despite the magnitude of the effect of a simple intervention[18]. Another opinion states that physical fitness applications on smartphones positively promote health behaviors [19]. Physical fitness is one of the health behaviors that need to be promoted in society. This is because someone who does regular exercise will have a positive effect on physical fitness, such as increasing aerobic capacity and increasing muscle strength, to lead a physically active life and are beneficial for health [5], [20]. Death from cancer, type 2 diabetes, hypertension, breast cancer, colon cancer, gestational diabetes, gallstone disease, ischemic heart disease, and ischemic stroke[21].

Smartphones are ideal for promoting physical activity in those with little motivation to exercise [22]. This is because almost all people have smartphones, so people can easily access information related to physical fitness. Based on the needs analysis, it is necessary to develop an Android-based physical fitness guide, to support physical fitness training independently. The physical fitness guide that will be developed is expected to be one of the people's motivations to do physical fitness exercises. In addition, these guidelines will be part of an effective strategy in promoting the importance of healthy and active living. Therefore, it is essential to develop android-based physical fitness activities. 
Based on the study results, it can be concluded that it is necessary to develop a physical fitness guide based on android software. This is reasonable to support the needs of the community's active lifestyle during a pandemic which is significantly constrained by the limited mobility that can be done. The developed physical fitness guide is expected to guide the community to carry out activities and measure physical fitness independently in their respective places.

\section{ACKNOWLEDGMENT}

Thanks to the Faculty of Sports Science, Yogyakarta State University, as the funder of the DIPA FIK UNY research and the students of the Faculty of Sports Science, so that this research can be carried out correctly.

\section{REFERENCES}

[1] B. F. Tavares et al., "Mobile applications for training plan using android devices: A systematic review and a taxonomy proposal," Inf., vol. 11, no. 7, 2020, doi: 10.3390/INFO11070343.

[2] D. V. S. Rao and D. T. M. Krishna, "A Design of Mobile Health for Android Applications," Am. J. Eng. Res., vol. 3, no. 6, pp. 20-29, 2014, [Online]. Available: www.ajer.org.

[3] T. Fühner, R. Kliegl, F. Arntz, S. Kriemler, and U. Granacher, "An Update on Secular Trends in Physical Fitness of Children and Adolescents from 1972 to 2015: A Systematic Review," Sport. Med., vol. 51, no. 2, pp. 303320, 2021, doi: 10.1007/s40279-020-01373-x.

[4] WHO, WHO Guidelines on physical activity and sedentary behaviour. 2020.

[5] Z. Birhanu and H. Gedefaw, "Physical Fitness Module," no. SpSc 1011, 2019.

[6] B. S. E. Rich, "ACSM???s Health-Related Physical Fitness Assessment Manual," Med. Sci. Sport. Exerc., 2004, doi: 10.1097/00005768-200409000-00030.

[7] S. Kolimechkov and S. Kolimechkov PHYSICAL, "European Journal of Physical Education and Sport Science PHYSICAL FITNESS ASSESSMENT IN CHILDREN AND ADOLESCENTS: A SYSTEMATIC REVIEW," Assess. Child. Adolesc. A Syst. Rev. Eur. J. Phys. Educ. Sport Sci., vol. 3, p. 66, 2017, doi: 10.5281/zenodo.495725.

[8] M. I. Z. R. B. Endang Rini Sukamti, "Profil Kebugaran Jasmani Dan Status Kesehatan Instruktur Senam Aerobik Di Yogyakarta," J. Olahraga Prestasi, vol. 12, no. 2, p. 116313, 2016, doi: 10.21831/jorpres.v12i2.11875.

[9] E. Füzéki, D. A. Groneberg, and W. Banzer, "Physical activity during COVID-19 induced lockdown: Recommendations," Journal of Occupational Medicine and Toxicology. 2020, doi: 10.1186/s12995-020-00278-9.

[10] C. Medina, A. Jáuregui, C. Hernández, T. Shamah, and S. Barquera, "Physical inactivity and sitting time prevalence and trends in Mexican adults. Results from three national surveys.," PLoS One, vol. 16, no. 7, p. e0253137, 2021, doi: 10.1371/journal.pone.0253137.

[11] R. S. Ervina, T. Eryando, and A. Prabawa, "Perancangan Sistem Informasi Pengukuran Kebugaran Jasmani (E-Bugar) Kementerian Kesehatan Ri," J. Manaj. Inf. Kesehat. Indones., vol. 8, no. 1, p. 14, 2020, doi: 10.33560/jmiki.v8i1.257.

[12] P. Polero et al., "Physical activity recommendations during COVID-19: Narrative review," Int. J. Environ. Res. Public Health, vol. 18, no. 1, pp. 1-24, 2021, doi: 10.3390/ijerph18010065.

[13] C. M.A., B. H.A., V. K.G., and P. M.S., "Accuracy of smartphone applications and wearable devices for tracking physical activity data," JAMA - J. Am. Med. Assoc., vol. 313, no. 6, pp. 625-626, 2015, [Online]. Available: http://www.embase.com/search/results?subaction=viewrecor d\&from=export\&id=L602187018\%0Ahttp://sfx.umd.edu/hs ?sid=EMBASE\&issn=15383598\&id=doi:\&atitle=Accuracy+ of + smartphone+applications + and + wearable + devices + for + tra cking+physical+activity+data\&stitle=JAMA\&ti.

[14] M. Zhou et al., "Personalizing Mobile Fitness Apps using Reinforcement," 2020.

[15] D. Clark et al., "Android application development to promote physical activity in adolescents," Proc. 2012 Int. Conf. Collab. Technol. Syst. CTS 2012, pp. 566-568, 2012, doi: 10.1109/CTS.2012.6261106.

[16] M. V. Villasana et al., "CoviHealth: Novel approach of a mobile application for nutrition and physical activity management for teenagers," PervasiveHealth Pervasive Comput. Technol. Healthc., pp. 261-266, 2019, doi: $10.1145 / 3342428.3342657$.

[17] Y. Setiakarnawijaya, E. Safadilla, E. A. Rahmadani, A. Robianto, and F. Fachrezzy, "Android-based physical fitness software guidance," J. Phys. Educ. Sport, vol. 21, no. September, pp. 2313-2319, 2021, doi: 10.7752/jpes.2021.s4295.

[18] S. S. Coughlin, M. Whitehead, J. Q. Sheats, J. Mastromonico, and S. Smith, "A Review of Smartphone Applications for Promoting Physical Activity.," Jacobs J. community Med., vol. 2, no. 1, pp. 1-14, 2016, [Online]. Available:

http://www.ncbi.nlm.nih.gov/pubmed/27034992\%0Ahttp://w ww.pubmedcentral.nih.gov/articlerender.fcgi?artid=PMC481 1195.

[19] A. Gabbiadini and T. Greitemeyer, "Fitness mobile apps positively affect attitudes, perceived behavioral control and physical activities," J. Sports Med. Phys. Fitness, vol. 59, no. 3, pp. 407-414, 2019, doi: 10.23736/S0022-4707.18.082609.

[20] M. A. van Baak et al., "Effect of different types of regular exercise on physical fitness in adults with overweight or obesity: Systematic review and meta-analyses," Obes. Rev., vol. 22, no. S4, pp. 1-11, 2021, doi: 10.1111/obr.13239.

[21] D. E. R. Warburton and S. S. D. Bredin, "Health benefits of physical activity: a systematic review of current systematic reviews," $\quad$ pp. $1-16, \quad 2017, \quad$ doi: 10.1097/HCO.0000000000000437.

[22] T. Harries, P. Eslambolchilar, R. Rettie, C. Stride, S. Walton, and H. C. Van Woerden, "Effectiveness of a smartphone app in increasing physical activity amongst male adults: A randomised controlled trial," BMC Public Health, vol. 16, no. 1, pp. 1-10, 2016, doi: 10.1186/s12889-016-3593-9. 